\title{
IMPLICAÇÕES DA PRÁTICA ESCOLAR NA CONSTRUÇÃO DE IDENTIDADES JUVENIS DE JOVENS EGRESSOS DO ENSINO MÉDIO ${ }^{12}$
}

\author{
IMPLICACIONES DE LA PRÁCTICA ESCOLAR EN LA CONSTRUCCIÓN DE \\ IDENTIDADES JUVENILES PARA EGRESADOS DE SECUNDARIA
}

\author{
IMPLICATIONS OF SCHOOL PRACTICE IN THE CONSTRUCTION OF YOUTH \\ IDENTITIES AMONG HIGH SCHOOL GRADUATES
}

\author{
Marlene HOLDORF ${ }^{3}$ \\ George Saliba MANSKE ${ }^{4}$ \\ Fabio $\mathrm{ZOBOLI}^{5}$
}

RESUMO: Estabelecemos análises sobre a construção identitária de jovens e algumas implicações relacionadas à função da escola enquanto formadora destes sujeitos. A pesquisa foi realizada a partir de questionário semiestruturado através de formulário eletrônico, assumindo uma abordagem qualitativa. O processo de escuta do sujeito jovem é interpretado nesta pesquisa como instrumento de captação da significação entre o vivido e o declarado, como uma possibilidade de interpretação das suas vivências possibilitando compreensões da função da escola em relação ao desenvolvimento de suas práticas. Apresentamos os desafios da inserção social dos jovens no mercado de trabalho, assim como, a transição do jovem para o mundo adulto e suas expectativas em relação a escola e aquilo que se desenvolveu naquele espaço. Consideramos a escola enquanto instituição educativa com vínculo em processos de construção social e histórica destes sujeitos que se apresentam num mundo globalizado em constante adequação e transformação.

PALAVRAS-CHAVE: Escola. Juventude. Identidades. Estudos Culturais.

\footnotetext{
${ }^{1}$ Pesquisa realizada com financiamento de bolsa de mestrado concedida pela CAPES por meio do Programa de Suporte à Pós-Graduação de Instituições de Ensino Comunitárias (PROSUC) para o Programa de Pós-Graduação em Educação, na área de concentração: Educação, da Universidade do Vale do Itajaí (UNIVALI).

${ }^{2}$ Este artigo conta com financiamento da Universidade Federal de Campina Grande (UFCG), estabelecido através de um convênio de Doutorado Interinstitucional em Educação (DINTER) com a Universidade Federal de Sergipe (UFS).

${ }^{3}$ Universidade do Vale do Itajaí (UNIVALI), Itajaí - SC - Brasil. Mestrado em Educação pelo Programa de Pósgraduação em Educação (PPGED) da UNIVALI. ORCID: https://orcid.org/0000-0002-1606-5437. E-mail: marleneholdorf@gmail.com

${ }^{4}$ Universidade do Vale do Itajaí (UNIVALI), Itajaí - SC - Brasil. Professor do Programa de |Pós-Graduação em Educação (PPGEDU) e do Programa de Pós-Graduação em Saúde e Gestão do Trabalho (PPGSGT). Doutorado em Educação (UFRGS). ORCID: https://orcid.org/0000-0003-0117-7927. E-mail: gsmanske@yahoo.com.br ${ }^{5}$ Universidade Federal de Sergipe (UFS), São Cristóvão - SE - Brasil. Professor do Programa de Pós-Graduação em Educação (PPGED). Doutorado em Educação (UFBA). Pós-Doutorado em "Educação do Corpo" pela Universidad Nacional de La Plata (UNLP) - Argentina. ORCID: https://orcid.org/0000-0001-5520-5773. E-mail: zobolito@gmail.com
}

RIAEE - Revista Ibero-Americana de Estudos em Educação, Araraquara, v. 16, n. 4, p. 2760-2775, out./dez. 2021. e-ISSN: 1982-5587 
RESUMEN: Establecimos análisis sobre la construcción identitaria de los jóvenes y algunas implicaciones relacionadas con el papel de la escuela como formadora de estos sujetos. La investigación se realizó a partir de un cuestionario semiestructurado a través de un formulario electrónico, asumiendo un enfoque cualitativo. El proceso de escucha del sujeto joven es interpretado en esta investigación como un instrumento para captar el significado entre lo vivido y lo declarado, como posibilidad de interpretar sus vivencias, posibilitando la comprensión del rol de la escuela en relación con el desarrollo de sus prácticas. Presentamos los desafios de la inserción social de los jóvenes en el mercado laboral, así como la transición de los jóvenes al mundo adulto y sus expectativas en relación con la escuela y lo que se ha desarrollado en ese espacio. Consideramos la escuela como una institución educativa vinculada a los procesos de construcción social e histórica de estos sujetos que se presentan en un mundo globalizado en constante adaptación y transformación.

PALABRAS CLAVE: Escuela. Juventud. Identidades. Estudios culturales.

ABSTRACT: We established analyses about the identity construction of young people and some implications related to the function of the school as a trainer of these subjects. The research was carried out using a semi-structured questionnaire through an electronic form, taking a qualitative approach. The process of listening to the young subject is interpreted in this research as an instrument to capture the meaning between what is experienced and what is stated, as a possibility of interpreting their experiences, making it possible to understand the function of the school in relation to the development of their practices. We present the challenges of the social insertion of young people in the job market, as well as the transition of young people to the adult world and their expectations in relation to school and what was developed in that space. We consider the school as an educational institution linked to processes of social and historical construction of these subjects who are presented in a globalized world in constant adaptation and transformation.

KEYWORDS: School. Youth. Identities. Cultural Studies.

\section{Introdução}

O processo de construção histórica de si mesmo nos possibilita pensar em aspectos culturais e cotidianos na produção de identidades em tempos e espaços relacionais. Tal constituição ocorre em grupos e coletividades, os quais passam a configurar culturas específicas com as quais indivíduos se identificam. No caso deste estudo esses processos incidem sobre jovens e os grupos juvenis em âmbito escolar e são a tônica e objeto de investigação.

Para Dayrell (2007, p. 1114), as vivências dos jovens em espaços escolares em um mundo globalizado se constituem numa condição juvenil complexa justamente por estarem "expostos a universos sociais diferenciados, a laços fragmentados, a espaços de socialização múltiplos, heterogêneos e concorrentes”. Em outras palavras, trata-se de confrontos de valores 
como resultados de multiprocessos de socialização, o que de certa forma torna o sujeito um "ator plural", com experiências variadas e por vezes contraditórias, forjando processos de identificação.

Compreendemos identidades como posições de sujeito não estáticas, percebidas por comportamentos, atitudes, ações que resultam dos movimentos transitórios de um corpo, dos seus deslocamentos contínuos e seus envolvimentos em tudo que encontra no curso e percurso de sua vivência; como aquilo que o indivíduo se torna a partir das suas experiências (LARROSA, 2018) e das escolhas nos e dos diferentes espaços e tempos, que se cruzam dentro de outros contextos, grupos ou relações e que de alguma forma determinam as ações/reações, o subjetiva e o constitui a partir do jogo das diferenças (HALL, 1997).

Nesse movimento de se tornar, de passar a ser e estar, percebe-se que supostamente a identidade tende a se fixar, mas, ao mesmo tempo, sua fixação não é possível (SILVA, 2014). Essas tendências, fundamentadas na teoria cultural e social pós-estruturalista, buscam descrever tanto os processos que procuram fixar as identidades quanto os que não permitem fixá-las, resultantes de movimentos subversivos, que as deslocam. A estes movimentos, Silva (2014) refere-se com metáforas como "diáspora, cruzamento de fronteiras, nomadismo".

A partir dessas marcações teóricas iniciais, acerca dos modos de produção de identidade de sujeitos, as questões juvenis marcam a atenção. O jovem, enquanto sujeito mediado por práticas que definem posicionamentos criando e recriando a si mesmo, tornou-se um tipo de sujeito a ser problematizado, e, mais especificamente, em seus modos de produção de identidades, em especial, ao que tange a este estudo, nas práticas escolares.

Referimo-nos às práticas escolares não somente como a descrição de todas as atividades realizadas, sejam elas institucionalizadas ou não, formais ou não formais, no âmbito escolar, mas sim, como pedagogias culturais que implicam a constituição de um modo de ser e estar no mundo, que ensinam e difundem verdades, através de jogos de poder, caracterizando-se como pedagogias culturais (COSTA; SILVEIRA; SOMMER, 2003).

Frente a esses apontamentos, consideramos pertinente debruçar-nos sobre a construção de identidades juvenis nos espaços escolares e, especificamente, entender como as práticas escolares se estabelecem no Ensino Médio na construção de identidades juvenis. O recorte da pesquisa abrange sujeitos de idade entre 18 e 24 anos, jovens já na transição para o mundo adulto, em busca da maioridade ou emancipação, mas enquadrados como um problema social, segundo proposições de Abramo (1997), que fundamenta esta transição do não enquadramento afirmando: não são jovens nem adultos. 
Para tanto, tivemos como questão de pesquisa a seguinte elaboração: como os jovens egressos do ensino médio regular, na faixa etária entre os 18 e 24 anos de idade, de uma escola de Educação Básica de um município do sul do Brasil entendem as práticas escolares enquanto mediadoras de um processo de construção de identidades?

Para atingir o objetivo já anunciado deste escrito, organizamos o mesmo a partir de mais outras três partes para além dessa introdução que recorta o objeto e apresenta alguns conceitos chaves de nosso estudo. Na segunda sessão do texto dissertamos e teorizamos o percurso metodológico utilizado no estudo. Na terceira sessão apresentamos as análises e discussões sobre o material empírico produzido. Na terceira e última parte tecemos nossas considerações finais.

\section{Metodologia}

Ao encontro da problemática da pesquisa, que aborda a temática da construção da identidade juvenil, e com o intuito de analisar a função da escola no que se refere à formação de identidades juvenis, foi realizada uma pesquisa de abordagem qualitativa, com uso de questionários como técnica de produção de dados.

O local em que foi desenvolvida a pesquisa trata-se de uma escola de Educação Básica com oferta de ensino fundamental anos iniciais e finais e ensino médio, em um município litorâneo do sul do Brasil, caracterizado por economicamente ser viabilizado pela construção civil e pelo turismo, apresentando uma população bastante expressiva e crescente a cada ano. Quanto à população fixa, a cidade possui 128 mil habitantes, podendo oscilar com picos de população flutuante até 4 milhões durante a temporada de verão (dezembro a fevereiro). Uma parte da população flutuante provém principalmente de outros estados brasileiros e de outros 06 (seis) dos 20 (vinte) países da América Latina, como Argentina, Paraguai, Colômbia, Haiti, República Dominicana e Venezuela. Estes trânsitos populacionais são importantes de serem demarcados pois influenciam diretamente na construção de valores sociais, culturais, educacionais e econômicos ${ }^{6}$, pela diversidade e multiculturalidade que compõem sujeitos e práticas presentes nas atividades escolares.

Em relação a seleção dos jovens a serem investigados, buscamos a participação daqueles que apresentaram contato eletrônico (via e-mail) nos registros escolares e que frequentaram e concluíram o Ensino Médio dentro do período de 2012 a 2018, pois

${ }^{6}$ Sob a lógica de operação do capital global na sua configuração neoliberal, a celebração da diferença tem efeito imediato e direto na produção de novos mercados. Afinal, quando mais diferenças, maior o nicho de produtos e consumidores. 
representavam os jovens de faixa etária entre 18 e 24 anos de idade, público-alvo da pesquisa $^{7}$.

A coleta de dados iniciou-se mediante contato com as entidades responsáveis pela escola e, posterior aprovação das gerências e direções, desenvolveu-se nas seguintes etapas: busca dos dados cadastrais dos alunos egressos no período já aludido; e-mail convite para participar da pesquisa; envio de formulário eletrônico, contendo o questionário semiestruturado de quatro questões obrigatórias relacionadas aos objetivos da pesquisa e uma questão relacionada à criação de um pseudônimo, elaborado em Formulário Eletrônico (via Google Forms) e enviado a todos os jovens egressos do período previsto na pesquisa.

Destacamos que no período elegido para a pesquisa havia um registro total de 1728 alunos na escola, porém, apenas 170 possuíam registro de contato cadastrado, sendo que boa parte desses estava desatualizado e, desse modo, o número total de retorno que tivemos foi drasticamente reduzido, em função de não retornarem os contatos. Na medida em que buscar informações pessoais como número pessoal de telefone e de aplicativos de mensagens, ou ainda, redes sociais, seria, ao nosso ver, demasiado invasivo, optamos, mesmo que com restrições de quantidade total de sujeitos participantes da pesquisa, manter apenas o contato via e-mail. Assim, tivemos 8 alunos/as egressos respondendo o questionário.

O questionário elaborado obedeceu a algumas regras básicas para sua constituição, partindo de uma lógica que expressasse de forma clara e objetiva a estrutura de aplicação e interpretação das questões. Na primeira parte do questionário, a preocupação foi com a identificação das informações da pesquisa. Em seguida, a entrevista se direcionava para as questões propriamente ditas. Nesta etapa de elaboração das quatro questões, tivemos o cuidado de desenvolver três perguntas de forma semiaberta e uma questão de forma fechada, todas devidamente enumeradas e elaboradas para que respondessem aos objetivos propostos. A preocupação com o questionário era de 'levantar, inventar, criar 'eixos norteadores', permitindo olhar e dizer coisas diferentes das que são olhadas e vistas, com outros óculos e linguagem, sobre e acerca do objeto bruto"(CORAZZA, 2016, p. 99).

As questões semiestruturadas apresentadas aos jovens foram as seguintes: Quais as práticas escolares vivenciadas por você? Você percebe alguma influência dessas práticas nas atividades atuais que realiza? Se sim, quais influências? Você percebe alguma relação entre sua formação escolar com situações de seu cotidiano? Se sim, quais? O que você espera da escola enquanto instituição social e formadora?

7 Esta pesquisa foi aprovada pelo "Parecer Consubstanciado do CEP de Número 3.427.468, datado em 01/07/2019", submetido na Universidade em que foi desenvolvida esta pesquisa.

RIAEE - Revista Ibero-Americana de Estudos em Educação, Araraquara, v. 16, n. 4, p. 2760-2775, out./dez. 2021. e-ISSN: 1982-5587 
Após recebermos as respostas e a separarmos em documento à parte, começamos a tecer as análises tomando os conceitos de pedagogia cultural, identidades e culturas, tal como já apresentado na introdução e mais bem explanado a seguir, em costura com o material empírico, como lentes teórico-analíticas para interpretação e compreensão das implicações das práticas escolares na produção dos jovens investigados.

Tais discussões se apresentam a seguir.

\section{Análise e discussão}

Coletados os registros nos questionários semiestruturados, seguimos para a organização dos dados da pesquisa e posterior análise e discussão. Nessa organização, a partir da compreensão de que culturas são formas de produção, por meio da linguagem, de significados partilhados (HALL, 1997), estabelecemos eixos que dizem respeito a tais formas de atribuição de sentido nas práticas apresentadas pelos jovens pesquisados, contemplando a problemática central da pesquisa e as provocações instaladas pelas perguntas do questionário aplicado. Assim, os eixos norteadores desta pesquisa situaram-se em dois grandes eixos de discussão: "Relação entre sua formação escolar com situações no seu cotidiano" e "Papel da escola: enquanto instituição social formadora". Cabe ressaltar que agrupamos nesses dois eixos norteadores as discussões abrangidas de forma mais ampla pelo questionário, visto que as respostas se conectavam fortemente nos argumentos apresentados.

a) Relação da formação escolar com situações de seu cotidiano

Importante ressaltar que, neste processo de escuta do sujeito jovem e da análise de suas narrativas, podemos encontrar uma possibilidade de compreendê-lo, perceber o papel da escola e desenvolver ações acerca da formação das noções de identidade, além de refletir sobre as implicações das práticas escolares no cotidiano. Neste eixo de discussão, as questões relacionadas especificamente à juventude permitiram interpretar o significado que atribuem as relações entre os processos vividos na escola e as práticas diárias, pós-escolares, em que está imerso.

Dentre as possibilidades apresentadas, nos chama atenção a relação entre continuidade de estudos e preparação para o mercado de trabalho, e ainda, de forma mais instigante, ao que 
intitulam de "mundo real". Conforme $\mathrm{M}^{8}$, "Sim alguns professores falavam muito sobre pensamentos crítico, e sobre ter ambições de vida, coisas que na época eu não entendia muito bem, mas que atualmente fazem muito sentido". Através de algumas práticas escolares, nos parece, que alguns professores instigam os sujeitos a uma formação crítica, porém, em outras situações, uma proposta de formação com ambições, muitas vezes delineadas por uma lógica de mercado que pauta práticas educacionais fomentadas nos espaços formais e informais de educação.

Propor aos/as alunos/as que analisem e interpretem o mercado, a economia, refletindo sobre um panorama educacional, mesmo que só à nível nacional, não é tarefa fácil, pois exige seleção de informação, conhecimento e criticidade. Assim também o é com a premissa de ter ambição na vida. Tais argumentos, de análise crítica para um mundo que pressupõem ambições, converge com o momento histórico em que vivemos, moldado sob um sistema neoliberal. Na esteira de processos educativos que se valem de termos tipicamente neoliberais (em especial a projeção de uma subjetividade empreendedora), é possível trazer à baila argumento de Veiga-Neto (2001, p. 38) sobre tal cenário econômico, quando afirma que em um mercado neoliberal a "liberdade deve ser continuamente produzida e exercida sob a forma de competição" para garantir a sua essência de existência.

Ainda neste sentido, importante mencionar que a vida e as subjetividades destes jovens estão constantemente sendo administradas no interior da governabilidade neoliberal, orientada de modo dominante para a movimentação e a gerência da economia do capitalismo tardio na sociedade globalizada (COSTA, 2011).

Em relação a disputas de formas de conhecimentos, tais como os de base humanista, como formar criticamente, e os forjados em linguagem econômica, como ter ambições, Sennett (2009 p. 39) relaciona o "embrutecimento do espírito" na era industrial em prol do instrumento de produção, disciplina e controle para um determinado tipo de sociedade de base econômica. $\mathrm{O}$ autor refere que emerge e se dissemina um corpo repensado a partir das técnicas e das práticas de comunicação que privilegiam o mercado, destituindo o humano em detrimento dos objetos que o alienam e legitimando formas de poder que são concebidas e produzidas por atores políticos, e que se movem e se conectam rapidamente às instituições formais e informais de educação, as quais também são redesenhadas para atender os interesses mercadológicos e econômicos.

${ }^{8}$ No questionário apresentado para respostas pelo formulário Google Docs, a primeira página apresentava o Termo de Consentimento Livre e Esclarecido (TCLE) para a pesquisa e, a seguir, o/a jovem poderia eleger um pseudônimo para a pesquisa. Desse modo, os nomes que aqui aparecem foram elencados pelos/as próprios jovens pesquisados.

RIAEE - Revista Ibero-Americana de Estudos em Educação, Araraquara, v. 16, n. 4, p. 2760-2775, out./dez. 2021. e-ISSN: 1982-5587 
$\mathrm{Na}$ legitimidade deste cenário, marcado pelos jogos de poder que determinam as formas de sujeição e também de governança da educação, mostram-se as redes de educação neoliberal, que para Ball (2006) são dispositivos que deslocam e rearranjam processos e práticas políticas e educacionais que rompem as fronteiras instituídas em todos os meios. Este rompimento autoriza governos, poderes e instituições a implantarem seus discursos.

Em nossas criações educacionais e discursivas, bem como projeções e ações, podemos perceber que as políticas são implementadas pelas mais variadas instituições, sejam elas públicas, privadas, mistas, ou ainda outras organizações ou núcleos emergentes, que re/criam a escola pelo domínio do capital. E esse processo é reescrito de tempos em tempos, adequando-se e reordenando-se mercados para a manutenção deste mesmo mercado, que centra suas práticas na utilização do sujeito sempre de modo a favorecer o ambiente externo.

Neste movimento de inclinação da escola para atender a este mercado neoliberal, aparecem dispositivos de controle e de regulação para uma produção a fim de ajustar a educação institucionalizada às intenções e especificidades empresariais. Nesse contexto, Ball (2006) sugere uma "política da identidade" centrada na descrição e análise das relações entre saber e poder através dos discursos e narrativas pelos quais eles são articulados.

Outras discussões também emergiram acerca do tópico das relações da escola com as práticas cotidianas, em direções diferentes daquelas apresentadas até então. Os argumentos seguintes podem ser agrupados em torno das características pragmáticas dos saberes institucionalizados disciplinares e seus usos no dia a dia. Por exemplo, Gio afirma que as disciplinas de "Matemática, Português, Física e Química são as matérias mais presentes no meu cotidiano". Ele destaca que estas disciplinas são as que mais usa na sua realidade diária, assim como Fabi Paola, que assevera que "o magistério serviu como base tanto na parte profissional como no dia a dia pessoal”. Fabi Paola afirma que o ensino profissionalizante, no seu caso o Magistério, trouxe influências para sua vida cotidiana.

Apontamentos de Costa, Silveira e Sommer (2003, p. 58) denotam que o magistério pode ser concebido como um curso que oportuniza relações de convivência, de troca de experiências, além de novas formas de conceber a escola, os conhecimentos e o currículo, havendo um entendimento do papel do/a professor/a como "produtor cultural" que privilegia práticas, mesmo que pautadas sob um "ideário emancipatório", e objetiva "formar cidadãos críticos e autônomos", levando em conta as experiências dos sujeitos e a sua participação, e atribuindo um caráter socialmente construído aos seus conhecimentos e experiências, num mundo em constante transformação de valores e representações. 
Podemos ressaltar, ainda, que a alusão a importância da escola no saber-fazer diário de jovens egressos está direcionada a transição e inserção do jovem em uma proposta de vida adulta, em que a utilização dos saberes possa convergir com as demandas e expectativas esperadas para esse momento da vida. Cabe ressaltar, no entanto, que as oportunidades de inserção na vida adulta se dão de forma desigual. Assim, a suposta preparação estritamente para um tipo de vida social adulta implica a não contextualização de outras formas de vida, inclusive com supressão da infância e juventude para muitas pessoas, e assim, a escola pode ser encarada em alguns momentos como "uma estrutura social perpassada pelos mecanismos de exclusão, que engendram uma segmentação escolar consequência de mutação estrutural sobre a natureza das próprias experiências" (DUBET, 2003, p. 30).

$\mathrm{O}$ referido autor pontua o desemprego e a fragilidade do jovem como resultado do distanciamento entre sua formação e sua colocação no mercado de trabalho, idealizado por um modelo que visa estritamente a formação profissional. Além disso, Dubet (2003, p. 30) salienta também um silogismo que indica que "já que todos os jovens egressos das grandes escolas ou dos cursos superiores tem um emprego, bastaria que todos os jovens atingissem esse nível de qualificação para que tivessem um emprego".

$\mathrm{Na}$ esteira desses argumentos, Castro e Abramovay (2002, p. 145-147) pontuam a questão da vulnerabilidade social como sendo também um importante recorte para os estudos voltados à juventude, com diversas possibilidades de análise voltadas para "indivíduos, domicílios e comunidades, além de recomendar que se identifiquem cenários e contextos". Em outras palavras, a abordagem pode se dar em distintos planos, como em estruturas sociais vulnerabilizantes ou em condicionantes de vulnerabilidades. O que as autoras propõem é uma compreensão das diversidades de situações e de sentidos existentes para os indivíduos dos multigrupos considerando "os novos perfis do mundo do trabalho ou do não-trabalho". Logo, as gerações juvenis, afetadas pelo desencanto e incertezas em relação ao futuro, demonstram que a escola e a família já não têm mais o mesmo sentido que tinham para as gerações passadas, as quais guardam identidades próprias e se construíram com outras referências (CASTRO; ABRAMOVAY, 2002).

Por fim, ainda no escopo das implicações da escola para vida diária, os excertos a seguir permitem considerações sobre as convivências com outras pessoas. Para Dri, acerca da relação entre sua formação escolar com situações de seu cotidiano, assevera: "Sim, relações pessoais e interpessoais"; e na esteira desses argumentos, Ana, por sua vez, afirma: “Aprendi a conviver com pessoas diferentes e a entender outras realidades no processo de socialização que a escola proporciona. Isso ajuda na formação pessoal de qualquer pessoa, independente da 
área que desejar seguir". Aqui, talvez, deva-se levar em consideração a atuação acadêmica de Ana. Ela preside a União de Estudantes no município que reside, e, portanto, é bastante ativa enquanto nos espaços estudantis, o que de certa forma pode ter contribuído para o seu entendimento de outras realidades no processo de socialização escolar. Ela também aponta a convivência, os processos de socialização e as relações pessoais como aspectos desenvolvidos pelas práticas e que apresentam conexão com o cotidiano. Outra participante, a Janaína, destaca de forma breve a relação da escola e suas práticas diárias: "Sim, lidar com as pessoas". Tanto Dri quanto Ana e Janaína apontam as relações pessoais como aspectos relevantes, ou seja, percebem que cotidianamente a vida se estabelece mediante relações entre pessoas e, consequentemente, entre grupos.

b) Papel da escola enquanto instituição social formadora

A escola cumpre uma função social e cultural relevante enquanto instância formadora de identidades. Isto se confirma com as narrativas dos jovens da pesquisa, que evidenciam seus anseios e necessidades falando do que esperam da escola e seu papel na formação de suas características sociais, culturais e pessoais. Valemo-nos do seguinte conjunto de excertos retirados das respostas elencadas pelos/as jovens para compor as discussões dessa seção:

Que mostre caminhos que cada um pode seguir, despertando habilidades individuais por meio de práticas conjuntas, oferecendo metodologias alternativas de ensino de acordo com as particularidades individuais de cada aluno, de forma que todos os formados possam sair com visões de mundo definidas; conhecendo no mínimo suas responsabilidades perante a sociedade (Bruno).

Espero que ela entenda seus alunos, nem todos são iguais cada dificuldade é diferente (Amor).

Penso que a escola precise ser um espaço favorável e facilitador da construção de conhecimentos que sejam aplicáveis à realidade dos alunos e que leve em consideração os fatores cognitivos envolvidos no processo de aprendizagem, possibilitando que esse processo seja construído com e para os alunos, que são diferentes entrei si e que aprendem de modos diferentes, repensar métodos de ensino e aprendizagem, e buscar inovações nessa área de conhecimento (M.)

Que ela forme cidadão crítico e formador de opinião, que seja cumpridor de seus deveres mas que também saiba seus direitos e possa contribuir perante a sociedade em que for inserido... (Dri).

Que o Estado possa investir na parte da infraestrutura, materiais $e$ capitação profissional dos professores e equipe escolar (Fabi Paola).

Espero melhoras para os próximos alunos! (Janaina)

Ensino de qualidade e valores... (Gio)

Espero que ela passe por uma reformulação, o método de ensino utilizado precisa ser alterado porque não condiz com as reais necessidades dos 
estudantes. E para que isso aconteça precisamos aumentar os investimentos na educação e não contingenciar (Ana).

Diante destas narrativas, constatamos que as angústias destes jovens egressos do Ensino Médio se dão em relação aos caminhos a seguir, a essa transição para o mundo do trabalho. Isso demanda, na menção de Santos e Moreira (2019), a elaboração de um currículo com e para este sujeito considerando suas experiências, suas diferenças e suas particularidades em relação à busca de novas práticas que contemplem as exigências de uma nova demanda escolar, considerando as peculiaridades dos grupos e indivíduos, no entanto, sem recair na lógica reprodutivista e formativa para sujeitos num mundo neoliberal.

Bauman (1999, p. 25) caracteriza esta nova demanda como sofredora de consequências culturais e éticas na atualidade por considerar as práticas de viver "sem alicerces", um cenário no qual os indivíduos devem enfrentar sozinhos o problema da ambivalência - socializados e ao mesmo tempo individualizados - mas com sentimento de liberdade no curso dos seus esforços autoconstrutivos. Nesse panorama há uma busca da certeza documentada na aprovação social, o que gera disputa entre grupos sociais e solidariedade humana.

Em meio a suas análises, Zygmunt Bauman, tem sinalizado para o modo instável em que vivemos, assim esses jovens são expressões e produtos de uma era cada vez mais líquida. A metáfora da liquidez em suas análises expressa o caráter evanescente e fugidio da atual fase da história, nova em muitos sentidos e com profundas mudanças na condição humana (COSTA, 2011).

As narrativas deste eixo retratam um jovem que quer contribuir com a sociedade, na busca de sua aprovação para se sentir inserido. Demonstra preocupação com o futuro. Indicam não se enquadrar mais num modelo de escola rígida, com propostas homogeneizantes, com tempos e espaços inflexíveis e disciplinadores, onde a formação moral se sobrepõe à ética, que propunha ao jovem uma interiorização da disciplina, da pontualidade, da obediência, convertendo-o à condição de aluno passivo e envolvendo-o nos estudos como um aprendiz de conhecimentos, sem levar em consideração a sua dimensão da juventude, tal como apontado por Dayrell (2007, p. 1119). Segundo o autor (DAYRELL, 2007, p. 1117-1118), enquanto a escola se mantiver na lógica de uma arquitetura "monolítica" ou rígida, buscando uma unificação e uma delimitação das ações dos jovens para "firmar-lhes o corpo, os conhecimentos, a moral", como se não houvesse outras possibilidades de transformar as práticas educativas ou de criar outras formas para estabelecer novas relações, estaremos 
reforçando a identidade de "“alunos' como se fosse [esta] a [sua] condição natural”, e não de um "vir a ser".

É, portanto, desafio da escola entender esta nova condição juvenil contemporânea, desmistificar esse entendimento de que a juventude está num "pretenso individualismo de caráter hedonista e irresponsável” (DAYRELL, 2007, p. 1117), e buscar compreender suas práticas e símbolos nesses novos modos de ser jovem. É nessa direção que o autor propõe uma inversão reflexiva, sugerindo que a escola deve ser repensada para atender, também, aos desafios da nova juventude.

Para Silva et al. (2017, p. 15), em termos mais abrangentes sobre o papel da escola, não só o conhecimento, mas o “currículo é também uma questão de identidade". Ele se constitui necessariamente numa relação de poder, seja pela determinação de conteúdos ou pela escolha do método de aplicação, e por privilegiar um tipo de conhecimento e não outro. Diferentes escolhas são feitas e induzem a subjetivação a um consenso, a uma hegemonia. Estas diferentes determinações de conteúdos e escolhas do método, que são "um produto do poder dos homens para definir o que é necessário e desejável”, segundo Louro (2000), nos levam a observar também a importância de analisarmos para quem e o porquê se fazem estas escolhas, considerando que as práticas de linguagem e do corpo são, por sua vez, efetivadas e propagadas pelas instâncias formadoras do indivíduo.

Ainda em Silva et al. (2017), repensar a escola, portanto, significa repensá-la a partir de um currículo que tome como base o significado de currículo (do latim curriculum), que significa "pista de corrida", e o que vem a ser identidade. O autor faz menção à pista como um espaço que promove um deslocamento, um curso, e considera as transformações do indivíduo envolvido nesse processo, o que ele é antes e o que se torna ao final do deslocamento. E isto se torna crucial para compreendermos o processo de implicações da prática escolar sobre a construção da identidade do sujeito, neste caso, dos jovens investigados.

Dayrell (2007, p. 1107) sugere repensarmos a escola e suas práticas educativas frente aos novos desafios que a juventude nos coloca, questionando se ainda é válida essa educação “de massa, homogeneizante com tempos e espaços rígidos, numa lógica disciplinadora, em que a formação moral predomina sobre a formação ética" num contexto flexível, dinâmico, fluído, onde predomina a individualidade e as identidades plurais do sujeito jovem.

Em suas colocações, o autor refere-se ao jovem como sujeito 
[...] que chega às escolas públicas, na sua diversidade, apresenta características, práticas sociais e um universo simbólico próprio que o diferenciam e muito das gerações anteriores. [...] a condição juvenil no Brasil manifesta-se nas mais variadas dimensões (DAYRELL, 2007, p. 1108).

As dimensões a que Dayrell (2007, p. 1108) se refere contemplam "o lugar social” que os jovens ocupam, pois definem o "limite e as possibilidades" com os quais eles constroem uma condição juvenil. Assim, compete a escola a tarefa de dialogar sobre esses limites e possibilidades junto com os jovens.

Tendo a escola, de certa forma, essa função de formação de identidades, infere-se que esta instituição pode fazer discursos éticos e sociopolíticos para garantia da dignidade humana no que tange à inserção do indivíduo ao meio social, cultural e político, bem como desconstruir crenças e reorganizar conceitos como identidade, diversidade, pluralidade e multiculturalidade, pois estes necessitam ser compreendidos e trabalhados enquanto elementos de constituição do sujeito. Silva (1995, p. 180) também se posiciona sustentando a ideia de que a escola, além de ocupar um espaço de domínio de saber culto, de raciocínio e método científico e filosófico bem como de elaboração literária da linguagem, também tem a capacidade de fazê-los de modo reflexivo e crítico.

Por sua vez, visto que os saberes se articulam historicamente, Louro (2000, p. 39) demonstra em suas pesquisas que as práticas do corpo e da linguagem das quais os jovens se utilizavam nas rodas de conversas, ou analisando os diários escritos por eles, constituíam sempre uma possibilidade para discutir e confidenciar questões ligadas à sexualidade, bem como um "espaço privilegiado para construção de saberes sobre nossos corpos e desejos". Narravam sobre seus "comportamentos ou modos de ser" como se isso estivesse impresso nas suas histórias de vida pessoal. A autora entende que tanto as práticas do corpo quanto as de linguagem produzem "marcas", e estas se efetivam e se propagam pelas instâncias formadoras do indivíduo, pois os corpos marcados são utilizados como referência para a sociedade.

Todas essas instâncias realizam uma pedagogia, fazem um investimento que, frequentemente, aparece de forma articulada, reiterando identidades e práticas hegemônicas enquanto subordina, nega ou recusa outras identidades e práticas; outras vezes, contudo, essas instâncias disponibilizam representações divergentes, alternativas, contraditórias. A produção dos sujeitos é um processo plural e também permanente (LOURO, 2000, p. 16).

Em concordância com Louro (2000), no que tange à produção dos sujeitos num processo plural e permanente, observa-se também que o papel do profissional da educação é o de instigar o jovem para que ele exponha seus pontos de vista, suas angústias, ansiedades, 
necessidades e desejos tanto pela linguagem oral como pela escrita, ou através da expressão corporal, até mesmo utilizando-se das novas tecnologias, para que, assim, desenvolva as competências de formular e elaborar conhecimentos, e com o intuito de que este mesmo sujeito se desloque da condição passiva de conhecimento para uma condição de propor e contrapor em garantia de seus direitos.

\section{Considerações finais}

Os processos educativos que permeiam os espaços e práticas escolares em suas implicações com a produção de identidades juvenis não ocorrem somente em uma configuração tradicional transmissiva de saberes, mas a partir de negociações da transição e da migração das diversas práticas oferecidas em relações dos cotidianos vivenciados e das expectativas geradas por diferentes cenários e sujeitos envolvidos nesses mesmos processos.

Nesses processos os jovens se referem repetidamente às práticas coletivas como as atividades físicas, rodas de conversa, atividades em equipe, círculo de amigos e participação em Grêmio Estudantil como aquelas que promovem as ações que seriam inerentes a escola, o que nos parece ser um indício de que há preocupação com a socialização, com o coletivo, com o ser humano, em busca de alicerces.

Partindo desse entendimento, práticas que reforçam convenções e estabelecem o lugar mesmo que cada sujeito deve ocupar na sociedade não são as mais creditadas pelos/as jovens pesquisados/as. A escola enquanto espaço de experimentação pode possibilitar aos educadores e mediadores um atuar mais consciente que resgate relações de conhecimento que aproximem estas áreas. Caberia, então, um reordenamento e deslocamento de poderes como formas de resistência, de fragilizar poderes vigentes e desencadear um realinhamento dos mesmos. Em torno das culturas juvenis, nesse caso.

Por fim, nos afeta na pesquisa a incidência de identidades juvenis que transitam em diálogos com a escola de modo que, por vezes, esperam dela o que o mundo adulto também lhes espera, mas por outro lado, aguardam que a escola possa dialogar com suas particularidades e lhes encoraje a seguir com seus próprios propósitos. Assim, compete aos sujeitos escolares constante movimento em um atuar que prima pela problematização, estranhando aquilo que é tido como ideal e certo, bem como, criando outras formas de conceber os sujeitos, o conhecimento, o currículo e a escola. 


\section{REFERÊNCIAS}

ABRAMO, H. W. Considerações sobre a tematização social da juventude no Brasil. Revista Brasileira de Educação: Departamento de Sociologia, Rio de Janeiro, v. 5-6, p. 25-36, maio, 1997. Quadrimestral. Disponível em:

http://anped.tempsite.ws/novo_portal/rbe/rbedigital/RBDE05_6/RBDE05_6_05_HELENA_ WENDEL_ABRAMO.pdf. Acesso em: 25 mar. 2019.

BALL, S. Sociologia das políticas educacionais e pesquisa crítico-social: uma revisão pessoal das políticas educacionais e da pesquisa em política educacional. Currículo sem Fronteiras, v. 6, n. 2, p. 10-32, 2006. Disponível em:

https://www.curriculosemfronteiras.org/vol6iss2articles/ball.pdf. Acesso em: 04 ago. 2021.

BAUMAN, Z. Modernidade e ambivalência. Trad. Marcus Penchel. Rio de Janeiro: Jorge Zahar Ed., 1999.

CASTRO, M. G.; ABRAMOVAY, M. Jovens em situação de pobreza, vulnerabilidades sociais e violências. Cadernos de Pesquisa, São Paulo, n. 116, p. 143-176, jul. 2002.

Disponível em: http://www.scielo.br/scielo.php?script=sci_arttext\&pid=S0100$15742002000200007 \& \operatorname{lng}=$ en\&nrm=iso. Acesso em: 12 out. 2019.

CORAZZA, S. M. Manual infame... mas útil, para escrever uma boa proposta de tese ou dissertação. Em Tese, v. 22, n. 1, p. 95-105, 2016. Disponível em:

http://www.periodicos.letras.ufmg.br/index.php/emtese/article/view/11157. Acesso em: 04 ago. 2021.

COSTA, M. V. Cartografando a gurizada da fronteira: novas subjetividades na escola. In: ALBUQUERQUE JÚNIOR, D. M.; VEIGA-NETO, A.; SOUZA FILHO, A. (org.).

Cartografias de Foucault. 2. ed. Belo Horizonte: Autêntica Editora, 2011. p. 269-294.

OSTA, M. V.; SILVEIRA, R. H.; SOMMER, L. H. Estudos culturais, educação e pedagogia. Rev. Bras. Educ., Rio de Janeiro, n. 23, ago 2003. Disponível em:

http://www.scielo.br/pdf/rbedu/n23/n23a03. Acesso em: 18 nov. 2019.

DAYRELL, J. A escola “faz” as juventudes? Reflexões em torno da socialização juvenil. In:

Educação \& Sociedade, Campinas, v. 28, n. 100, p.1105-1128. 2007.

DUBET, F. A escola e a exclusão. Cadernos de pesquisa, n. 119, p. 29-45, 2003. Disponível em: https://www.scielo.br/j/cp/a/JBTWwBmFCfZBxm9QKbxSN9C/?format=pdf\&lang=pt. Acesso em: 04 ago. 2021.

HALL, S. A centralidade da cultura: notas sobre as revoluções culturais do nosso tempo. Educação e Realidade: Cultura, mídia e educação, Porto Alegre, v. 22, n. 2, p. 1542, jul./dez. 1997. Disponível em:

https://seer.ufrgs.br/educacaoerealidade/article/view/71361/40514. Acesso em: 27 abr. 2019.

LARROSA, J. Tremores: escritos sobre experiência. Trad. Cristina Antunes, João Wanderley Geraldi. 1. ed. 3. reimp. Belo Horizonte: Autêntica Editora, 2018. p.15-34 (Coleção Educação: Experiência e Sentido). 175 p. 
LOURO, G. L. (org.). O corpo educado. Pedagogia da sexualidade. Trad. Tomaz Tadeu da Silva. 2. ed. Belo Horizonte: Autêntica, 2000.

SANTOS, J. P. L.; MOREIRA, N. R. Articulando currículo, prática e cultura: exigências formativas que impactam a escolarização de mulheres negras no Ensino Superior brasileiro. Revista Tempos Espaços Educação, São Cristóvão, v. 12, n. 31, p. 233-254, out./dez. 2019. Disponível em: https://seer.ufs.br/index.php/revtee/article/view/10678. Acesso em: 12 ago. 2021.

SENNETT, R. A corrosão do caráter: As consequências pessoais do trabalho no novo capitalismo. Trad. Marcos Santarrita. 14. ed. Rio de Janeiro: Record, 2009. 204 p.

SILVA, T. T. Os novos mapas culturais e o lugar do currículo numa paisagem pós-moderna. In: SILVA, T. T.; MOREIRA, A. F. Territórios contestados: o currículo e os novos mapas políticos e culturais. 4. ed. Petrópolis, RJ: Vozes, 1995. Cap. 8, p. 184-202 (Coleção Estudos Culturais em Educação).

SILVA, T. T.; HALL, S.; WOODWARD, K. Identidade e diferença: a perspectiva dos estudos culturais. Petrópolis, RJ: Vozes, 2014. 133 p.

SILVA, T. T. et al. Documentos de identidade: uma introdução às teorias do currículo. 3. ed. 9. reimp. Belo Horizonte: Autêntica Editora, 2017. 156 p.

VEIGA-NETO, A. Olhares. In: COSTA, M. V. (org.). Caminhos Investigativos: novos olhares na pesquisa em educação. 2. ed. Rio de Janeiro: DP\&A, 2002. p. 23-38.

\section{Como referenciar este artigo}

HOLDORF, M.; MANSKE, G. S.; ZOBOLI, F. Implicações da prática escolar na construção de identidades juvenis de jovens egressos do ensino médio. Revista Ibero-Americana de Estudos em Educação, Araraquara, v. 16, n. 4, p. 2760-2775, out./dez. 2021. e-ISSN: 19825587. DOI: https://doi.org/10.21723/riaee.v16i4.15387

Submetido em: 10/07/2021

Revisões requeridas em: 16/08/2021

Aprovado em: 18/09/2021

Publicado em: 21/10/2021 